\title{
ПУТЕШЕСТВУЯ ВО ВРЕМЕНИ И ПРОСТРАНСТВЕ (к юбилею Э.Р. Усмановой)
}

\author{
(C) 2018 г. М.В. Бедельбаева
}

\begin{abstract}
Статья посвящена биографии и некоторым результатам работ неординарного и яркого представителя археологического сообщества Казахстана - Э.Р. Усмановой. Сфера ее научных интересов включает изучение андроновской культуры в ритуальном контексте поведения человека, реконструкцию костюма эпохи бронзы. В своей деятельности она в полной мере реализует сочетание археологического и музеологического интереса, являясь автором ряда музейных экспозиций и куратором выставок.
\end{abstract}

Ключевые слова: археология, Э.Р. Усманова, эпоха бронзы, Верхнее Притоболье, археологическая культура, реконструкция, музейный проект

Эмма Радиковна Усманова родилась 28 сентября 1958 года в г. Караганде. В 1965-1969 гг. училась в СШ № 59, в 1970 - в школе-интернате г. Москвы, в 1971-1975 гг. - в СШ № 3 в г. Караганде. В 1975 г. поступила на исторический факультет КарГУ, который закончила в 1980 г. В течение года (1980-1981) работала учителем в восьмилетней школе с. Крещеновка Осакаровского района Карагандинской области. Затем работала в историко-краеведческом музее г. Жезказгана старшим научным сотрудником, заведующей отделом досоветского периода. С 1985 г. по настоящее время является научным сотрудником КарГУ им. академика Е.А. Букетова. Участник многих казахстанских и зарубежных научно-исследовательских и археологических экспедиций, руководитель Лисаковской археологической экспедиции, автор четырех монографий и более 100 публикаций по археологии и древней истории Казахстана.
Таковы строки официальной биографии Э.Р. Усмановой. Но... уникальность и многогранность личности Эммы Радиковны, превратности и метаморфозы ее судьбы не позволяют ограничиться лишь этим лаконичным форматом.

В детстве мама Эммы Р.Л. Хуснуллина [историк-античник по образованию, ученица казанского историка А. Шофмана - прим. авт.] подарила Эмме знаковые книги: «Мифы древней Греции» А. Куна и «Аку-Аку» Т. Хейердала. Прочитав их запоем, она начала грезить о великих археологических открытиях. Впервые предметно столкнулась с археологией в кружке Московского Дворца пионеров и школьников, когда ее мама училась в аспирантуре МГУ. Занятия вел известный ученый Борис Григорьевич Петерс - старший научный сотрудник сектора античной археологии Института археологии АН СССР, автор более 100 научных статей и книг по античной, восточной, средневековой и 
Бедельбаева М.В. Путешествуя во времени и пространстве...

подводной археологии. В дальнейшем многие из слушателей этого кружка, закончив МГУ, стали известными учеными. Б.Г Петерс умел разбудить в своих питомцах жажду познания древности и уже в 11 лет Эмма принимает участие в первой экспедиции на раскопках славянского городища в Ступино в Московской области.

Следующим решительным шагом в археологию стал кружок юных археологов во Дворце пионеров г. Караганды, где наставниками школьников был ныне известный российский археолог Геннадий Борисович Зданович, а также студенты истфака В. Варфоломеев, В. Калинин, Н. Иванова, И. Янцен и руководитель археологического кабинета в КарГУ М. Хабдулина.

Поступив на исторический факультет КарГУ, Э. Усманова уже твердо знала, что будет заниматься археологией. Именно университетские преподаватели Г.Б. и С.Я. Здановичи, В.В. Евдокимов смогли поддержать ее стремление и воплотить детские мечты. И, конечно же, экспедиции, манившие романтикой с ранней юности. Еще студенткой Э.Р. Усманова принимала участие в составе ЦКАЭ в исследованиях поселения Атасу, ставшего хрестоматийным памятником Центрального Казахстана. Большую роль в ее археологическом формировании сыграл М.К. Кадырбаев, исследователь с незаурядным мышлением и интеллектом. Позднее это были раскопки поселений Ак Мустафа, Мыржык, Кент, могильников Шет, Ак Мустафа, Сангыру, Атасу. Студенческой археологической практикой в университете в те годы руководил молодой препода- ватель С.У. Жауымбаев. В 1977 г. под руководством В.В. Евдокимова студенты исследовали поселение Семиозерное (Костанайская обл.) и именно тогда, как считает Эмма Радиковна, ей была передана эстафета изучения памятников Верхнего Притоболья.

Всё складывалось, как видим, вполне удачно для молодого археолога. И тут произошел, на первый взгляд, неожиданный, но при ближайшем рассмотрении - вполне предсказуемый поворот в судьбе. В 20 лет она стала участницей подпольной организации «Юный коммунар», которая была признана органами КГБ антисоветской. К счастью участников группы не осудили, но последствия были: талантливую студентку, обладателя стипендии им. Н.К. Крупской Эмму Усманову лишили именной стипендии, а при распределении не позволили остаться работать в КарГУ - слишком очевидным был диссонанс между поведением будущего молодо-

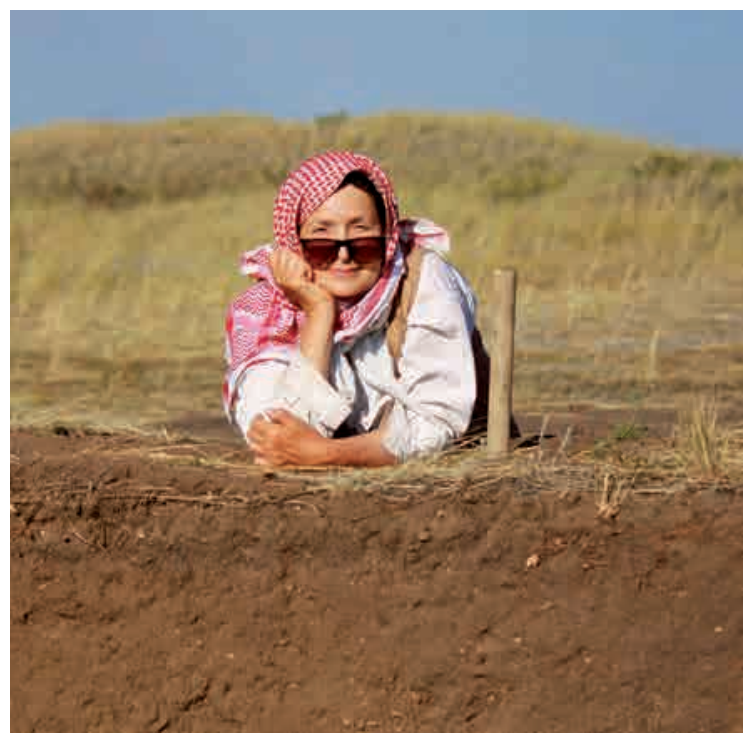

Эмма Радиковна Усманова. Фото Н. Гончаровой, 2008 г

Emma Radikovna Usmanova. Photo by N. Goncharova, 2008 
го специалиста и существовавшими на тот момент реалиями «партийного» исторического факультета.

Так, молодой специалист Усманова получила распределение в маленькую деревушку Крещеновка в Осакаровском районе. Работа в сельской школе потребовала от Эммы Радиковны разносторонних компетенций и позволила пройти хорошую жизненную школу. Показательна запись в ее трудовой книжке, где говорится о преподавании не только истории, но и физкультуры, биологии. Молодая учительница достойно справилась со всеми трудностями и приобрела новых друзей в лице коллегучителелей.

Следующие три года жизни, проведенные в Жезказгане, были насыщены работой в краеведческом музее и, одновременно, Доме пионеров, где по инициативе Э.Р. Усмановой был открыт кружок «Эх, раскопаем!». В течение трех лет эти ребята участвовали в исследованиях поселений и могильников Атасу, Мыржык, Ак Мустафа. В качестве руководителя детской экспедиции Э.Р. Усманова самостоятельно исследовала бегазинский могильник Уйтас Айдос и курганы средневековых кочевников в Улытауском районе. В рамках кружка Эмма Радиковна воспитала целую когорту романтиков и благодарные бывшие ученики до сих пор остаются самыми надежными её друзьями и единомышленниками, разделяя с ней счастливые минуты жизни и всегда готовые помочь в решении ее проблем.

С 1985 г. по настоящее время Э.Р. Усманова плодотворно работает научным сотрудником музея археологии и этнографии КарГУ им. Е.А. Букетова и среди различных научных исследований приоритетным направ- лением для неё всегда было и остаётся изучение эпохи бронзы Верхнего Притоболья. Без преувеличения можно сказать, что руководство Лисаковской археологической экспедиции стало основным делом её жизни.

История экспедиции насчитывает более 30 лет. Была сформирована команда единомышленников, зараженных энтузиазмом начальника экспедиции и готовых работать, что называется «не за деньги, а за совесть». В общей сложности Лисаковская экспедиция в разрезе всех лет её деятельности - это около тысячи профессионалов и любителей из Алматы, Астаны, Жезказгана, Караганды, Костаная, Сатпаева, Петропавловска, Москвы, Челябинска, СанктПетербурга, Екатеринбурга, Уфы, Казани, Калининграда, Днепропетровска, Минска, Киева, Львова, Таллина, Сантьяго де Чили, Копенгагена. Сама Эмма Радиковна считает, что секрет успешных археологических раскопок на берегах реки Тобол, это, прежде всего, команда экспедиции, ее люди, коллеги и волонтеры Лисаковской археологической экспедиции и сама атмосфера города. Как справедливо пишет В.В. Ткачев [к.и.н., доцент, СНС Института степи Уральского отделения РАН, Оренбург, РФ - прим. авт.]: «Это исследовательский проект “с человеческим лицом”... Лисаковская экспедиция обрела международный статус не в результате межгосударственных соглашений, а благодаря духовному единению обычных людей, бескорыстно участвующих в общем благородном деле» [Ткачев, 2013, c. 12].

Отдельного упоминания заслуживает вклад администрации города в исследование древней истории. Городские власти и предприятия, Костанайское управление культуры, 
Бедельбаева М.В. Путешествуя во времени и пространстве...

меценаты-бизнесмены и просто жители города Лисаковска всегда организационно (а порой и материально) поддерживали работу экспедиции. По инициативе Э.Р. Усмановой и при личном участии был создан Лисаковский музей истории и культуры Верхнего Притоболья, куратором которого она является и в настоящее время. Заслугой Эммы Радиковны является то, что ее детище награждено Золотой медалью как лучший музей ближнего зарубежья на Межрегиональном Общественном открытом конкурсе «Музей года Евразия - 2008» (г. Екатеринбург, Россия). Руководство и жители региона по достоинству оценили большой личный вклад Эммы Радиковны в изучение истории родного края она награждена званием «Почетный гражданин г. Лисаковска», является лауреатом премии «Казына» Костанайского клуба меценатов в номинации «Культурное наследие» (2007).

Научные итоги работы Лисаковской экспедиции состоят в исследовании компактной группы относительно синхронных памятников Верхнего Притоболья, образующих целый археологический микрорайон, связанный с функционированием обособленной производственной структуры. Особенностью изученных памятников является органичное сочетание алакульских и федоровских традиций, что играет определяющую роль в решении андроновской проблемы. С коллекциями работали ученые из США и Великобритании. В научном сообществе по достоинству оценена высокая степень достоверности целой серии радиоуглеродных дат этого памятника, сопряженных с дендрохронологическими исследованиями и другими уточняющими междисциплинарными методами. Комплексность в изучении археологических объектов характеризует принципы работы Э.Р. Усмановой: это анализ антропологических и остеологических коллекций, вопросы палеодемографии, социокультурные реконструкции, реконструкция костюма эпохи бронзы, варианты интерпретации ритуалов, консервация и реставрация, а также культурологический контекст тысячи артефактов.

Э.Р. Усманова имеет богатый опыт музееведения: является одним из авторов экспозиции музея археологии и этнографии КарГУ им. Е.А. Букетова, автором экспозиций Жезказганского историко-археологического музея, музея-заповедника СулайманТоо (Ош, Кыргызстан), заповедникамузея «Улытау». За активную работу в сфере музейной деятельности в 2015 г. Э.Р. Усманова была отмечена нагрудным знаком Министерства культуры и спорта РК «Мәдениет саласының үздігі» («Лучший работник культуры»). В 2016 г. она вошла в состав Казахстанского Национального комитета Всемирного наследия при Национальной комиссии РК по делам ЮНЕСКО и ИСЕСКО (Исламская организация по вопросам образования, науки и культуры).

Участник множества исследовательских проектов и международных программ, она постоянно совершенствуется в профессиональном и научном плане: стажировалась в Карнегимузее (г. Питсбург, США, 2004), в Оксфорде (Великобритания, 2004), участник тренинга по консервации и музеоологии (г. Хиросима, Япония, 2005), единственная участница из стран СНГ в программе «Сохранение культурного наследия» (США, 2009), участник проекта «Пастушество и доместикация лошади азиатской степи в доисторическое время» (Университет г. Эксетера, Великобритания), ку- 
ратор от Казахстана международного проекта по изучению ДНК древнего населения эпохи бронзы (Копенгагенский университет, Музей естественной истории Дании, Центр биогенетики (Дания), Музей Кон-Тики (Норвегия)). Постоянный участник международных Евразийских археологических конгрессов и конференций Европейской Археологической Ассоциации (FICEA Измир, 2007; ЕАА Стамбул, 2014; Вильнюс, 2016; Маастрихт, 2017; Барселона, 2018).

Ее познания в области культурологии, музееведения, дизайна, фотографии, этнографии, семиотики, фольклористики удивляют, а умение использовать эти знания в области археологических реалий ушедших эпох является результатом глубокого анализа, симбиоза научного и популярного жанров и ...безграничной фантазии, без которой немыслимо ни одно научное открытие. Знание языков позволяет активно путешествовать и география этих поездок завораживает, с трудом поддаваясь подсчету. Это десятки стран, сотни встреч и знакомств, тысячи фотографий. На основе собственных высококачественных профессиональных снимков она разрабатывает дизайны буклетов и специальных изданий. Одно из таких изданий, подготовленное совместно с журналистом Е.Н. Кузнецовой и фотографами Г. и В. Жувакиными, посвящено исследованию историкокультурного ландшафта Карлага как части архпелага ГУЛАГ.

Особый интерес вызывают ее эссе, написанные в формате воспоминаний, - о М.К. Кадырбаеве, К.А. Акишеве, Е.Е. Кузьминой, Ж. Курманкулове, В.В. Евдокимове. Знаковое место в ее археологической судьбе занимают известные российские ученые из Института востоковедения РАН Д.С. Ра- евский и Е.В. Антонова, из Института археологии РАН - Н.Я Мерперт. Археологический опыт формировался участием в исследованиях Хорезмской археологической экспедиции (Л.М. Левина, 1993, 1994 гг.), в Термезской экспедиции (Т.К. Мкртычев, 1995 г.). Культурологические познания совершенствовались в Казахском научно-исследовательском институте по проблемам культурного наследия номадов (2009-2011). До сих пор не расстается Эмма Радиковна и со своим жезказганским «гнездом», работая куратором в Национальном историко-культурном и природном заповеднике-музее «Улытау».

И везде, где работала и работает Эмма Радиковна, она трудится с большой самоотдачей, креативно, генерирует новые идеи и формы работы. В качестве примера приведем один из её новых успешно состоявшихся проектов - Фестиваль древних технологий и культурных коммуникаций «Desh-Thor» памяти Тура Хейердала, проведенный 3-5 августа 2018 г. в Лисаковске совместно с коллегами из Алматы, Петропавловска, Челябинска, Екатеринбурга.

Закончить эту статью хотелось бы в стиле, более характерном для самой Эммы Радиковны - эмоциональном. Речь пойдет о тех качествах, которые, видимо, предопределила сама судьба, когда мама нарекла будущего учёного именем «Эмма». Это было сделано по просьбе деда Эммы Радиковны, который будучи солдатом Советской армии в годы второй мировой войны попал в плен и прошёл через суровые испытания в одном из самых страшных лагерей для военнопленных в районе города Бохум (Германия). Не ожесточившись сердцем, оставив в нём место для любви и веры в будущее, он привёз из далё- 
Бедельбаева М.В. Путешествуя во времени и пространстве...

кой страны это имя для своей первой внучки. И с тех пор, буквы этого имени задают основной алгоритм жизни Эммы Радиковны.

«Э» - энтузиазм; «М»- мно-

гогранность; «М» - мудрость;
«А»- аскетизм, в котором проявляется личностный стержень Эммы Радиковны Усмановой - безграничная преданность археологии.

\section{ЛИТЕРАТУРА}

1. Ткачев В.В. С любовью вглубь тысячелетий // Памятники Лисаковской округи: археологические сюжеты: сб. ст. / Отв. ред. Э.Р. Усманова. Караганда-Лисаковск: Tengri Ltd, 2013. C. 11-14.

\section{Список основных публикаций Э.Р. Усмановой}

Монографии:

Накосные украшения эпохи бронзы Казахстана. Лисаковск, 1999. 64 с. (в соавт. с Логвинымм В.Н.).

Могильник Лисаковский I: факты и параллели. Караганда-Лисаковск, 2005. 232 с.

Костюм женщины эпохи бронзы Казахстана. Опыт реконструкций. КарагандаЛисаковск, 2010. 176 с., ил.

Памятники Лисаковской округи: археологические сюжеты: сб. ст. / Отв. ред. Э.Р. Усманова. Караганда-Лисаковск: Tengri Ltd, 2013. 336 с.

Статьи на русском языке:

Элитные погребения в обряде племен андроновской общности // Верования и культы домусульманской Средней Азии. М.: Государственный музей Востока, 1997. С. 63-65.

Женский головной убор и его семиотический статус в древних культурах Евразии. Woman's Headdress and its semiotic status in ancient Eurasian cultures // Historical and Linguistic interaction between Inner Asia and Europe. Hungari, Szeged, 1997. P. 391-400.

Памятники II в. до н.э. - І в. н.э. в урало-казахстанских степях // Приаралье в древности и средневековье. М.: Изд. фирма «Восточная литература» РАН, 1998. С. 151155. (в соавт. с Боталовым С.Г.).

Реконструкция костюма из могильника Дашти-Козы // ВААЭ. 2001. Вып. 3. С. 73-79 (в соавт. с Потемкиной T.М.).

«Мировая Гора» и сакральное пространство в андроновском погребальном обряде (по материалам могильника Лисаковский) // Северная Евразия в эпоху бронзы. Пространство. Время. Культура. Барнаул: изд-во Алт. ун-та, 2002. С. 132-135.

«Андроновская» предтеча текстильных кочевых технологий (по материалам могильников Лисаковский округи) // Роль номадов в формировании культурного наследия Казахстана: сб. матер. Междунар. научн. конф. (г. Алматы, 23-24 апреля 2009). Алматы: Print-S, 2010. C. 321-328.

Этноархеологическая реконструкция феномена кыстау (зимовки) // Кадырбаевские чтения-201: матер. III Междунар. научн. конф. Актобе, 2012. С. 492-499.

Погребения монгол-буддистов конца XIII - начала XIV в. из Центрального Казахстана // Древние культуры Северного Китая, Монголии и Байкальской Сибири. Пекин: Science Press, 2015. Т. 2. С. 515-523 (в соавт. с Дремовым И.И., Панюшкиной И.П.).

Презентация андроновского костюма в экспозиции музея (по материалам могильника Лисаковский эпохи бронзы) // Поволжская археология. 2017. № 3 (21). С. 289-304.

Бусы из египетского фаянса из казахстанских памятников андроновской общности // История и археология Семиречья. Алматы, 2017. Вып. 5. С. 40-54 (в соавт. с Лихтер Ю.А.). 


\section{Статьи на иностранных языках:}

Calendar Age of Lisakovsky timbers attributed to Andronovo community of Bronze Age in Eurasia // Radiocarbon, 2008. № 50 (3), 459-469 (в coaвm. с Panyushkina I.P., Mills B.J., Li Cheng).

Horses for the dead funerary foodways in Bronze Age Kazakhstan // Antiquity, 2011. № 85, 116-128 (в coaвm. с Outram A.K., Stear N.A., Kasparov A., Varfolomeev V., Evershed R.P., etc.).

Frauenkleidung - zum Stand der Textiltechnologie in der Bronzezeit Unbekanntes Kasachstan. Archäologie im Herzen Asiens. Bochum: Deutsches Bergbau-Museum, 2013. Band I. S. 315-323 (в coarm. c Sylvia Mitschke).

Dental health, diet, and social transformations in the Bronze Age: Comparative analysis of pastoral populations in northern Kazakhstan // Quaternary International, 2014, 1-17 (в coaвm. c Ventresca Miller A., Logvin V., Kalieva S., Shevnina I., Logvin A., Kolbina A., Suslov A.).

Subsistence and social change in central Eurasia: stable isotope analysis of populations spanning the Bronze Age transition // JAS. 2014. Vol. 42, 525-528 (в coabm. c Ventresca Miller A., Logvin V., Kalieva S., Shevnina I., Logvin A., Kolbina A., Suslov A., Privat K., Haas K., Rosenmeier M.).

Dental health, diet, and social transformations in the Bronze Age: Comparative analysis of pastoral populations in northern Kazakhstan // Quaternary International. 2014. Vol. 348, 130-146 (в coabm. c Ventresca Miller A., Logvin V., Kalieva S., Shevnina I., Logvin A., Kolbina A., Suslov A.).

The extent of cereal cultivation among the Bronze Age to Turkic period societies of Kazakhstan determined using stable isotope analysis of bone collagen // JAS. 2015. Vol. 59. Elsevier Science B.V., Amsterdam. P. 23-34. (в coaвm. с Motuzaite Matuzeviciute G., Lightfoot E., Loman V., O'Connell T.C., Voyakin D., Liu X., Svyatko S., Jones M.K.).

Early indicators to $\mathrm{C} 4$ plant consumption in central Kazakhstan during the Final Bronze Age and Early Iron Age based on stable isotope analysis of human and animal bone collagen // Archaeological Research in Asia, 1-18. Journal homepage: www.elsevier.com/locate/ ara (в coaвm. с Ananyevskaya E., Aytqaly A., Beisenov A., Dmitriev E., Garbaras A., Kukushkin I., Loman V., Sapolaite J.).

Pastoralist Mobility in Bronze Age Landscapes of Northern Kazakhstan: $87 \mathrm{Sr} / 86 \mathrm{Sr}$ and $\delta 180$ Analyses of Human Dentition from Bestamak and Lisakovsk // Environmental Archaeology, 2017. Published online 31 October 2017: http:// www.tandfonline.com/doi/f ull/10.1080/14614103.2017.1390031 (в coabm. c Ventresca Miller A., Winter-Schuh C., Logvin A., Shevnina I. \& Makarewicz C.A.).

137 ancient human genomes from across the Eurasian steppes // Nature. 17 may 2018. Vol 557 \# 7705, 369-374. https://doi.org/10.1038/s41586-018-0094-2 (в coaвm. c Peter de Barros Damgaard, Marchi N., Rasmussen S., Peyrot M., Renaud G., Korneliussen T., Moreno-Maya V.J., Pedersen M.W., Goldberg A., etc.).

Ancient hepatitis B viruses from the Bronze Age to the Medieval period // Nature. 17 may 2018. Vol 557 \# 7705, 418-423https://doi.org/10.1038/s41586-018-0094-2 (в coabm. c Miihlemarm B. , Jones Terry C., Damgaard Peter de Barros, Allentoft Morten E., Shevnina I., Logvin A., etc.).

\section{Сведения об авторе:}

Бедельбаева Марина Васильевна - кандидат исторических наук, заведующая музеем археологии и этнографии, Сарыаркинский археологический институт, Карагандинский государственный университет им. Е.А. Букетова (г. Караганды, Казахстан); bmv_1967@mail.ru 
Бедельбаева М.В. Путешествуя во времени и пространстве...

\section{УАҚЫТ ПЕН КЕНІСТІКТЕГІ САЯХАТ (Э.Р. Усманованың мерейтойына арналған)}

\section{М.В. Беделбаева}

Мақала Қазақстан археология қоғамдастығының аса бір көрнекті өкілі Э.Р.Усманованың өмірі мен ғылыми жұмыстарының нәтижелеріне арналған. Ғалымның ғылыми зерттеу аясына Андронов мәдениетін адамгершілік мінезқұлық жағдайында зерттеу, қола дәуірінің костюмдерін қайта құру кіреді. Оның осы бағыттағы қызметінде археологиялық және мұражайлық қызығушылықтарының бір-бірімен әдемі үйлесімділік тапқанын ғалымның мұражайлық экпозициялар мен көрмелердің тәлімгері болуынан көреміз.

Түйін сөздер: археология, Э.Р. Усманова, қола дәуірі, Жоғарғы Тобыл маңы, археологиялық мәдениет, қайта құру, мұражай жобасы

\section{TRAVELING IN TIME AND SPACE (for the anniversary of E.R. Usmanova)}

\section{M.V. Bedelbayeva}

The article is devoted to the biography and some results of the work of an extraordinary and bright representative of the archaeological community of Kazakhstan E. R. Usmanova. As a scientist she studies the Andronovo culture in the ritual context of human behavior and reconstructs the clothes of people of the Bronze Age. In her activities archaeological and museological interests are combines- she is the author of a number of museum expositions and exhibitions curator.

Keywords: archaeology, E.R. Usmanova, Bronze Age, Upper Tobolye, archaeological culture, reconstruction, museum project

\section{REFERENCES}

1. Tkachev, V. V. 2013. In Usmanova, E. R. (ed.) Pamyatniki Lisakovskoy okrugi: arkheologicheskiye syuzhety (The sites of the Lisakovsk area: archaeological scenes). Karaganda-Lisakovsk: "Tengri Ltd” Publ., 11-14 (in Russian).

\section{About the Author:}

Bedelbayeva Marina V. Candidate of historical sciences, director Archaeology and ethnography museum, Saryarka archaeological Institute, Karagandy State University after academician E.A. Buketov, Karagandy, Kazakhstan; bmv_1967@mail.ru 